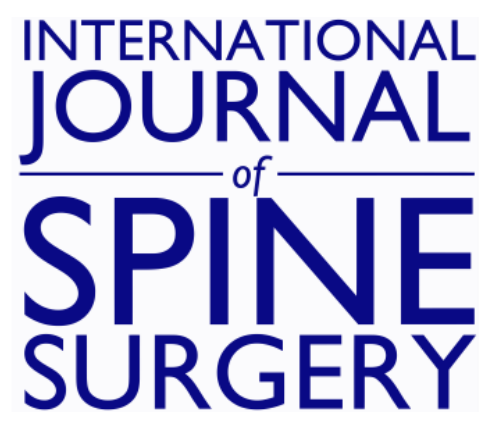

\title{
Comparison of Clinical and Radiographic Outcomes After Standalone Versus Cage and Plate Constructs for Anterior Cervical Discectomy and Fusion
}

Islam Fayed, Anthony G. Conte, Gregory Keating, Kelsey D. Cobourn, Marcelle Altshuler, Erini Makariou, Steven M. Spitz, Amjad N. Anaizi, M. Nathan Nair, Jean-Marc Voyadzis and Faheem A. Sandhu

Int J Spine Surg 2021, 15 (3) 403-412

doi: https://doi.org/10.14444/8060

http://ijssurgery.com/content/15/3/403

This information is current as of April 26, 2023.

Email Alerts Receive free email-alerts when new articles cite this article. Sign up at: http://ijssurgery.com/alerts 


\title{
Comparison of Clinical and Radiographic Outcomes After Standalone Versus Cage and Plate Constructs for Anterior Cervical Discectomy and Fusion
}

\author{
ISLAM FAYED, MD, MS, ${ }^{1}$ ANTHONY G. CONTE, MD,${ }^{1}$ GREGORY KEATING, MD, ${ }^{2}$ \\ KELSEY D. COBOURN, MD,${ }^{1}$ MARCELLE ALTSHULER, $\mathrm{MD},{ }^{2}$ ERINI MAKARIOU, $\mathrm{MD},{ }^{3}$ \\ STEVEN M. SPITZ, MD ${ }^{1}$ AMJAD N. ANAIZI, MD ${ }^{1}$ M. NATHAN NAIR, MD, MPH, ${ }^{1}$ \\ JEAN-MARC VOYADZIS, MD, ${ }^{1}$ FAHEEM A. SANDHU, MD, PHD ${ }^{1}$ \\ ${ }^{I}$ MedStar Georgetown University Hospital, Department of Neurosurgery, Washington, DC, ${ }^{2}$ Georgetown University School of Medicine, Washington, DC, \\ ${ }^{3}$ MedStar Georgetown University Hospital, Department of Radiology, Washington, DC
}

\begin{abstract}
Background: Anterior cervical discectomy and fusion (ACDF) has conventionally been performed using an allograft cage with a plate-and-screw construct. Recently, standalone cages have gained popularity due to theorized decreases in operative time and postoperative dysphagia. Few studies have compared these outcomes. Here, we directly compare the outcomes of plated versus standalone ACDF constructs.

Methods: A single-center retrospective review of patients undergoing ACDF after June 2011 with at least 6 months of follow up was conducted. Clinical outcomes were analyzed and compared between standalone and plated constructs. Multivariate regression analysis of the primary outcome, need for revision surgery, as well as several secondary outcomes, procedure duration, estimated blood loss (EBL), length of hospital stay, disposition, and incidence of dysphagia, hoarseness, or surgical site infection, was completed.

Results: A total of 321 patients underwent ACDF and met inclusion-exclusion criteria, with mean follow-up duration of 20 months. Forty-six (14.3\%) patients received standalone constructs, while $275(85.7 \%)$ received plated constructs. Fourteen $(4.4 \%)$ total revisions were necessary, 4 in the standalone group and 10 in the plated group, yielding revision rates of $8.7 \%$ and $3.6 \%$, respectively $(P=.125)$. Mean EBL was $98 \mathrm{~mL}$ in the standalone group and 63 $\mathrm{mL}$ in the plated group $(P=.001)$. Mean procedure duration was 147 minutes in the standalone group and 151 minutes in the plated group $(P=.800)$. Mean hospital stay was 3.6 days in the standalone group and 2.5 days in the plated group $(P=.270)$. There was no significant difference in incidence of dysphagia $(P=.700)$ or hoarseness $(P=.700)$.

Conclusions: Standalone ACDF demonstrates higher, but not statistically significant, revision rates than plateand-screw constructs, without the hypothesized decreased incidence of dysphagia or hoarseness and without decreased procedure duration or EBL. Surgeons may consider limiting use of these constructs to cases of adjacent segment disease. Larger studies with longer follow up are necessary to make more definitive conclusions.

Level of Evidence: 4.

Clinical Relevance: This study will help spine surgeons decide between using standalone or cage-and-plate constructs for ACDF.

Cervical Spine

Keywords: anterior cervical discectomy and fusion, standalone, anterior plate, pseudarthrosis, dysphagia
\end{abstract}

\section{INTRODUCTION}

Anterior cervical discectomy and fusion (ACDF) is a well-established "gold standard" surgical option for the treatment of symptomatic cervical degenerative disc disease refractory to conservative intervention. ${ }^{1,2}$ After satisfactory decompression of the neural elements, the goal of fusion is to reestablish stability across the affected segments, correct loss of cervical lordosis, and maintain intervertebral discspace height. Traditionally, this has been achieved with the use of an interbody cage or bone graft and an anterior cervical plating system, the introduction of which has dramatically increased fusion rates while maintaining lordosis and decreasing the incidence of cage subsidence or dislocation. ${ }^{3}$ However, despite its efficacy, anterior plating has also been implicated in the risk of transient or chronic dysphagia, tracheoesophageal and neurovascular injury, and development of adjacent segment disease (ASD). ${ }^{3}$ 
To reduce complications associated with anterior plating, anchored standalone cage systems have recently gained popularity due to a theorized decrease in operative time, blood loss, impact on adjacent discs, and postoperative dysphagia. ${ }^{4,5}$ Despite these potential benefits, spinal surgeons must consider the risk of nonunion, subsidence, and progressive cervical kyphosis when using standalone cages, particularly for multilevel disease.

Several recent studies have attempted to compare standalone and plated constructs, yet outcome data remain at a clinical equipoise, particularly regarding fusion rates and postoperative dysphagia. ${ }^{3,6-8}$ The objective of this study is to add a larger single-institution case series to the literature that directly compares the outcomes of plated versus standalone ACDF constructs as an index procedure with respect to revision rate, perioperative metrics, postoperative dysphagia, and hoarseness.

\section{METHODS}

A single-center retrospective case series of all index ACDF procedures performed by 5 spine fellowship trained attending neurosurgeons since the implementation of our institution's electronic medical record in June 2011 was conducted. All patients were 18 years of age or older and had at least 6 months of follow up. Patients were excluded if age was less than 18 years, follow-up duration was less than 6 months, if a prior cervical spine surgery was performed, or if surgery was performed due to trauma, neoplasm, or infection. Polyetheretherketone (PEEK) cages were used in all cage-and-plate constructs, with a variety of different plating systems. The Zero-P (DePuy Synthes, Raynham, MA), Coalition MI (Globus), or Scarlet (Spineart) standalone devices were used for standalone cases. Bone graft material varied by attending surgeon preference and included demineralized bone matrix allograft in most cases, as well as autograft bone from the anterior lip of the superior vertebral body, ViviGen cellular bone matrix (Johnson and Johnson, New Brunswick, NJ), Trinity Elite allograft (Orthofix, Lewisville, TX), BioBurst allograft (Burst Biologics, Boise, ID), or MagnetOs biphasic calcium phosphate bone graft (Kuros Biosciences, Schlieren, Switzerland). Demographic, perioperative, outcomes, and radiographic data were collected. Our primary outcome was need for revision surgery. Procedure duration; estimated blood loss (EBL); length of hospital stay (LOS); disposition to home versus rehabilitation; hospital readmission; and incidence of dysphagia, hoarseness, or surgical site infection (SSI) were collected as secondary outcomes. Dysphagia was recorded if documented in progress or clinic notes or if the patient was prescribed steroids or speech and language pathology therapy for swallowing. Hoarseness was recorded if documented in progress or clinic notes. In addition, postoperative cervical spine parameters - cervical lordosis, cervical sagittal vertical axis (SVA), and T1 slope - and successful fusion defined as a change in interspinous distance on dynamic radiographs of $\leq 2 \mathrm{~mm}^{9-11}$ were measured by an attending neuroradiologist for patients who had imaging available.

\section{Statistical Analysis}

After the collection of demographic data from the electronic medical record, basic descriptive statistics were calculated on Excel (Microsoft, Redmond, WA). Patients were divided into 2 groups: standalone versus plated constructs. These groups were compared for significant differences in demographic data using the Kruskal-Wallis equality of populations test for continuous variables or the Fisher exact test for categorical variables. Next, a multivariate regression was performed in which the independent variables were age, gender, body mass index (BMI), surgical diagnosis (myelopathy, radiculopathy, or deformity), diabetes, smoking, number of levels fused, attending surgeon performing the operation, and use of a standalone or plated construct (primary variable); and the dependent variables were need for revision surgery (primary outcome, binary); procedure duration; EBL; LOS; disposition (binary); hospital readmission (binary); and incidence of dysphagia, hoarseness, or SSI (binary). Radiographic parameters were compared between groups based on type of construct and need for revision using Welch's unpaired $t$ tests assuming unequal variances. Statistical analyses were performed using Stata (StataCorp, College Station, TX) with a prospectively determined $P$ value of $<.05$ taken to indicate significant difference for all analyses. These statistical analyses predominantly compared means of groups; as such, a small number of missing data points had minimal effect on the overall analysis. 
Table 1. Demographic data.

\begin{tabular}{|c|c|c|c|c|}
\hline & Standalone & Plated & Total & $P$ Value \\
\hline No. patients (\%) & $46(14.3)$ & $275(85.7)$ & $321(100)$ & \\
\hline Age, mean $\pm \mathrm{SD}, \mathrm{y}$ & $58.1 \pm 1.9$ & $57.7 \pm 0.7$ & $57.8 \pm 0.6$ & .722 \\
\hline Male, \% & 43.5 & 37.1 & 38.0 & .416 \\
\hline Female, $\%$ & 56.5 & 62.9 & 62.0 & \\
\hline Body mass index, mean $\pm \mathrm{SD}$ & $29.8 \pm 1.0$ & $30.5 \pm 0.6$ & $30.4 \pm 0.5$ & .784 \\
\hline Myelopathy, \% & 63.0 & 25.8 & 31.2 & $.001^{\mathrm{a}}$ \\
\hline Radiculopathy, \% & 32.6 & 70.9 & 65.4 & \\
\hline Deformity, \% & 4.4 & 3.3 & 3.4 & \\
\hline Diabetes, $\%$ & 26.1 & 18.9 & 19.9 & .318 \\
\hline Smoking, \% & 30.4 & 21.8 & 23.1 & .255 \\
\hline Number of levels, mean \pm SD & $1.9 \pm 0.1$ & $2.2 \pm 0.1$ & $2.2 \pm 0.1$ & $.032^{\mathrm{a}}$ \\
\hline Attending surgeon & & & & $.001^{\mathrm{a}}$ \\
\hline Follow-up, mean $\pm \mathrm{SD}$, mo & $18.3 \pm 2.0$ & $18.2 \pm 0.8$ & $18.2 \pm 0.7$ & .439 \\
\hline
\end{tabular}

${ }^{\mathrm{a} P}$ values $<.05$ are statistically significant.

\section{Study Design and Ethics}

This study adheres to the Strengthening the Reporting of Observational Studies in Epidemiology guidelines. This study was approved by our institutional review board and did not require patient consent due to the retrospective nature of the analysis.

\section{RESULTS}

A total of 321 patients underwent ACDF and met inclusion and exclusion criteria, with a mean followup duration of $18.2 \pm 0.7$ months. Forty-six $(14.3 \%)$ patients received standalone constructs, while $275(85.7 \%)$ received plated constructs. Mean age was $58.1 \pm 1.9$ years in the standalone group, $57.7 \pm 0.7$ years in the plated group, and $57.8 \pm 0.6$ years overall. Kruskal-Wallis and Fisher exact tests showed no differences between groups in age, gender, BMI, diabetes, smoking, and follow-up duration. There were differences between groups, however, in the surgical diagnosis, attending surgeon, and number of levels fused. More patients in the standalone group underwent surgery due to myelopathy as opposed to radiculopathy $(63.0 \%$ and $32.6 \%$, respectively), and more patients in the plated group underwent surgery due to radiculopathy as opposed to myelopathy $(70.9 \%$ and $25.8 \%$, respectively; $P=.001)$. One attending surgeon used more standalone constructs than the others $(P=$ .001). Fewer levels were fused per operation using

Table 2. Revision rates. ${ }^{a}$

\begin{tabular}{lccc}
\hline & Standalone & Plated & Total \\
\hline Revisions (total cases) & $4(46)$ & $10(275)$ & $14(321)$ \\
Revision rate, $\%$ & 8.7 & 3.6 & 4.4 \\
\hline${ }^{\mathrm{a}} P=.125$. & & &
\end{tabular}

standalone than plated constructs $(1.9 \pm 0.1$ versus $2.2 \pm 0.1, P=.032)$. Demographic data are listed in detail in Table 1.

Fourteen total revision surgeries were performed, yielding an overall revision rate of $4.4 \%$. Four revisions $(8.7 \%)$ were performed in the standalone group, and 10 revisions $(3.6 \%)$ were performed in the plated group $(P=.125)$. These revisions were performed due to $\mathrm{ASD}$, hardware failure, or persistent-recurrent compression of neural elements. All 4 revisions in the standalone group were on Zero-P devices. Revision rates are listed in Table 2. We then performed a multivariate regression as described in the Methods. Despite the higher revision rate in the standalone group, that variable did not reach statistical significance in the multivariate regression $(P=.186)$. Furthermore, age $(P=.644)$, gender $(P=.396)$, BMI $(P=.767)$, surgical diagnosis $(P=.707)$, diabetes $(P=.899)$, smoking $(P=.796)$, number of levels fused $(P=$ $.866)$, and attending surgeon $(P=.446)$ also did not have a significant effect on revision rate. Results of the multivariate regression analysis are listed in Table 3.

The multivariate regression also included several secondary outcome measures as dependent variables: procedure duration; EBL; LOS; disposition; hospital readmission; and incidence of dysphagia, hoarseness, or SSI. Procedure duration was significantly affected by gender $(P=.001)$, number of levels fused $(P=.001)$, and attending surgeon $(P=$ $.001)$. Mean procedure duration was $147 \pm 7$ minutes in the standalone group and $151 \pm 3$ minutes in the plated group $(P=.800)$. EBL was significantly affected by smoking $(P=.053)$, number of levels fused $(P=.001)$, attending surgeon $(P=$ $.024)$, and standalone constructs $(P=.001)$. Mean EBL was $98 \pm 22 \mathrm{~mL}$ in the standalone group and 
Table 3. Multivariate regression analysis ( $P$ values).

\begin{tabular}{|c|c|c|c|c|c|c|c|c|c|}
\hline & Age & Gender & $\begin{array}{l}\text { Body Mass } \\
\text { Index }\end{array}$ & Diagnosis & Diabetes & Smoking & Levels & Surgeon & Standalone \\
\hline Revision rate & .644 & .396 & .767 & .707 & .899 & .796 & .866 & .446 & .186 \\
\hline Procedure duration & .305 & $.001^{\mathrm{a}}$ & .524 & .986 & .651 & .222 & $.001^{\mathrm{a}}$ & $.001^{\mathrm{a}}$ & .800 \\
\hline Estimated blood loss & .537 & .520 & .191 & .203 & .497 & $.053^{\mathrm{a}}$ & $.001^{\mathrm{a}}$ & $.024^{\mathrm{a}}$ & $.001^{\mathrm{a}}$ \\
\hline Length of stay & .992 & .628 & .246 & .063 & $.010^{\mathrm{a}}$ & .151 & .177 & .207 & .270 \\
\hline Dysphagia & .924 & .815 & .802 & .411 & .811 & .266 & $.001^{\mathrm{a}}$ & .134 & .700 \\
\hline Hoarseness & $.045^{\mathrm{a}}$ & .593 & .276 & .760 & .115 & .576 & $.041^{\mathrm{a}}$ & $.005^{\mathrm{a}}$ & .700 \\
\hline Disposition & .184 & $.009^{\mathrm{a}}$ & .512 & $.047^{\mathrm{a}}$ & $.030^{\mathrm{a}}$ & .491 & .995 & .921 & .978 \\
\hline Readmission & .178 & .646 & .704 & .282 & .863 & .383 & .894 & $.032^{\mathrm{a}}$ & .214 \\
\hline Surgical site infection & .546 & .199 & .529 & .501 & .058 & .431 & .764 & .707 & $.030^{\mathrm{a}}$ \\
\hline
\end{tabular}

${ }^{a} P$ values $<.05$ are statistically significant.

$63 \pm 3 \mathrm{~mL}$ in the plated group $(P=.001)$. LOS was significantly affected by diabetes $(P=.010)$. Mean LOS was $3.6 \pm 0.9$ days in the standalone group and $2.5 \pm 0.2$ days in the plated group $(P=.270)$. Incidence of dysphagia was significantly affected by number of levels fused $(P=.001)$. In the standalone group, $19.6 \%$ of patients experienced dysphagia compared with $19.6 \%$ of patients in the plated group $(P=.700)$. Incidence of hoarseness was significantly affected by age $(P=.045)$, number of levels fused $(P=.041)$, and the attending surgeon $(P$ $=.005)$, with higher incidence occurring with increasing age, increasing number of levels, and decreasing surgeon level of experience. In the standalone group, $4.4 \%$ of patients experienced hoarseness compared with $3.6 \%$ of patients in the plated group $(P=.700)$. Disposition to home versus rehabilitation was significantly affected by gender $(P$ $=.009)$, diagnosis $(P=.047)$, and diabetes $(P=$ .030). In the standalone group, $6.5 \%$ of patients were discharged to rehabilitation compared with $3.3 \%$ of patients in the plated group $(P=.978)$. Attending surgeon had a significant effect on hospital readmission $(P=.032)$. In the standalone group, $2.2 \%$ of patients were readmitted compared with $4.0 \%$ of patients in the plated group $(P=.214)$. The most common reason for readmission was dysphagia: $50 \%$ of cases with no difference between plated and standalone groups. Other reasons were unrelated medical issues. Incidence of SSI was significantly affected by standalone constructs, with a rate of $2.2 \%$ in the standalone group and $0.0 \%$ in the plated group $(P=.030)$. Secondary outcomes are listed in Table 4.

Of the 321 total patients, 180 had postoperative plain radiographs available for review. When comparing groups based on standalone versus plated constructs, there was no significant difference in cervical lordosis $\left(14.7 \pm 1.8^{\circ}\right.$ versus $12.9 \pm$ $\left.0.8^{\circ}, P=.366\right)$, cervical SVA $(24.7 \pm 3.4 \mathrm{~mm}$ versus $22.0 \pm 1.2 \mathrm{~mm}, P=.450)$, or T1 slope $(26.1$ $\pm 2.0^{\circ}$ versus $\left.26.6 \pm 0.6^{\circ}, P=.811\right)$. When comparing the revision group to the nonrevision group, there was no difference in cervical lordosis $\left(10.6 \pm 2.6^{\circ}\right.$ versus $\left.13.3 \pm 0.7^{\circ}, P=.343\right)$, cervical SVA $(28.9 \pm 4.8 \mathrm{~mm}$ versus $22.0 \pm 1.2 \mathrm{~mm}, P=$ $.195)$, or T1 slope $\left(24.7 \pm 1.6^{\circ}\right.$ versus $26.6 \pm 0.6^{\circ}$, $P=.279)$. Of these patients, 21 had dynamic (flexion-extension) radiographs $\geq 6$ months postoperatively available for review. In the standalone group, $87.5 \%(7 / 8)$ of patients had a change in interspinous distance $>2 \mathrm{~mm}$ compared with $38.5 \%(5 / 13)$ of patients in the plated group $(P=$ $.017)$. In the revision group, $33.3 \%(1 / 3)$ of patients had a change in interspinous distance $>2 \mathrm{~mm}$ compared with $61.1 \%(11 / 18)$ of patients in the nonrevision group $(P=.489)$. Radiographic parameters are listed in Table 5.

Table 4. Secondary outcomes.

\begin{tabular}{|c|c|c|c|c|}
\hline & Standalone & Plated & Total & $P$ Value \\
\hline Procedure duration, mean $\pm \mathrm{SD}$, min & $147 \pm 7$ & $151 \pm 3$ & $150 \pm 3$ & .800 \\
\hline Estimated blood loss, mean $\pm \mathrm{SD}, \mathrm{mL}$ & $98 \pm 22$ & $63 \pm 3$ & $68 \pm 4$ & $.001^{\mathrm{a}}$ \\
\hline Length of stay, mean $\pm \mathrm{SD}, \mathrm{d}$ & $3.6 \pm 0.9$ & $2.5 \pm 0.2$ & $2.7 \pm 0.2$ & .270 \\
\hline Dysphagia, \% & 19.6 & 19.6 & 19.6 & .700 \\
\hline Hoarseness, \% & 4.4 & 3.6 & 3.7 & .700 \\
\hline Disposition, $\%$ rehab & 6.5 & 3.3 & 3.7 & .978 \\
\hline Readmission, \% & 2.2 & 4.0 & 3.7 & .214 \\
\hline Surgical site infection, \% & 2.2 & 0.0 & 0.3 & $.030^{\mathrm{a}}$ \\
\hline
\end{tabular}

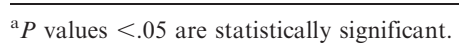




\begin{tabular}{|c|c|c|c|c|c|c|}
\hline & \multicolumn{3}{|c|}{ By Construct } & \multicolumn{3}{|c|}{ By Revision Status } \\
\hline & Standalone & Plated & $P$ Value & Revision & Nonrevision & $P$ Value \\
\hline Cervical lordosis, mean $\pm \mathrm{SD},{ }^{\circ}$ & $14.7 \pm 1.8$ & $12.9 \pm 0.8$ & .366 & $10.6 \pm 2.6$ & $13.3 \pm 0.7$ & .343 \\
\hline Cervical sagittal vertical axis, mean $\pm \mathrm{SD}, \mathrm{mm}$ & $24.7 \pm 3.4$ & $22.0 \pm 1.2$ & .450 & $28.9 \pm 4.8$ & $22.0 \pm 1.2$ & .195 \\
\hline $\mathrm{T} 1$ slope, mean $\pm \mathrm{SD}{ }^{\circ}$ & $26.1 \pm 2.0$ & $26.6 \pm 0.6$ & .811 & $24.7 \pm 1.6$ & $26.6 \pm 0.6$ & .279 \\
\hline Change in interspinous distance $>2 \mathrm{~mm}, \%$ & 87.5 & 38.5 & $.017^{\mathrm{a}}$ & $33.3 \%$ & $61.1 \%$ & .489 \\
\hline
\end{tabular}

${ }^{\mathrm{a}} P$ values $<.05$ are statistically significant.

\section{CASE ILLUSTRATION}

The patient is 76-year-old woman with multiple prior thoracolumbar spinal surgeries who presented to the emergency department with 2 weeks of bilateral lower extremity weakness and sharp pain between her shoulders. On physical examination, she had full strength in bilateral upper extremities and 4 out of 5 strength diffusely in bilateral lower extremities. Her sensation was intact, and she had urinary incontinence at baseline. Dynamic radiographs of the cervical spine demonstrated mobile anterolisthesis at C4-5 and C7-T1 that worsened with flexion and improved with extension (Figures A and B). Magnetic resonance imaging of the cervicothoracic spine showed disc osteophyte complexes with moderate canal stenosis at $\mathrm{C} 4-5$ and severe canal stenosis at C7-T1 (Figures C-E). Given these findings, she underwent $\mathrm{C} 4-5$ and $\mathrm{C} 7-\mathrm{T} 1$ ACDFs using standalone constructs without complication. Postoperative plain radiographs showed good placement of these constructs, but the screw at C7 was parallel to the disc space due to difficulty obtaining a more favorable angle due to restriction by the sternum (Figures $F$ and $G$ ). She recovered well from this operation, then also underwent revision of her prior thoracolumbar fusion during the same hospital stay, after which she was discharged to a subacute rehabilitation facility.

The patient had done well at the rehabilitation facility, but her 6-week postoperative radiographs showed hardware failure with anterior displacement of the C7-T1 standalone construct (Figures $\mathrm{H}$ and I). This was confirmed with a computed tomography scan (Figures $\mathbf{J}$ and $\mathrm{K}$ ) and may have been due to poor fixation of the integrated screws and/or poor intraoperative fluoroscopic visualization at the C7-T1 level. She was readmitted to the hospital and underwent a revision of the C7-T1 ACDF, with removal of hardware and replacement with a cage and anterior plate and screws. Postoperative radiographs showed that this new construct was well positioned (Figures L and M). She recovered well from this operation and was discharged back to her rehabilitation facility to continue physical therapy.

\section{DISCUSSION}

ACDF is one of the most efficacious treatments in a spine surgeon's armamentarium for the treatment of cervical myelopathy, radiculopathy, or deformity. ${ }^{1,5,11,12}$ The introduction of anterior plating to enhance stability after insertion of an interbody cage has drastically increased fusion rates, while subsequently lowering the incidence of subsidence, pseudarthrosis, or progressive kyphosis. ${ }^{2}$ Anterior plating, though effective, has been implicated in the development of dysphagia, hoarseness, ASD, and increased operative time and blood loss. Complications, including tracheoesophageal injury and plate-screw migration, though rare, have been reported. To mitigate these factors, the screwanchored standalone interbody cage was introduced. $^{4,5,13}$ Various studies have presented similar fusion rates of standalone cages to standard cageand-plate systems; however, evidence of the standalone cage's ability to improve patient outcomes and limit adverse events and complication rates remains inconclusive.

\section{Revision Rate}

The current body of literature varies tremendously in the reported outcomes of standalone versus cage-and-plate constructs for ACDF. Many studies report a greater incidence of subsidence, pseudarthrosis, or progressive kyphosis with standalone cages, ${ }^{14-18}$ while others report outcomes comparable with those of plated constructs. ${ }^{19-27}$ A few recent meta-analyses pooled some of these studies to report outcomes over a larger sample size. The largest meta-analysis pooled 19 studies and showed significantly less subsidence and better restoration of cervical lordosis in the plated group, albeit with a higher rate of ASD. ${ }^{6}$ The next largest meta-analysis pooled 15 studies and showed no difference in fusion rates or incidence of subsidence or ASD, 

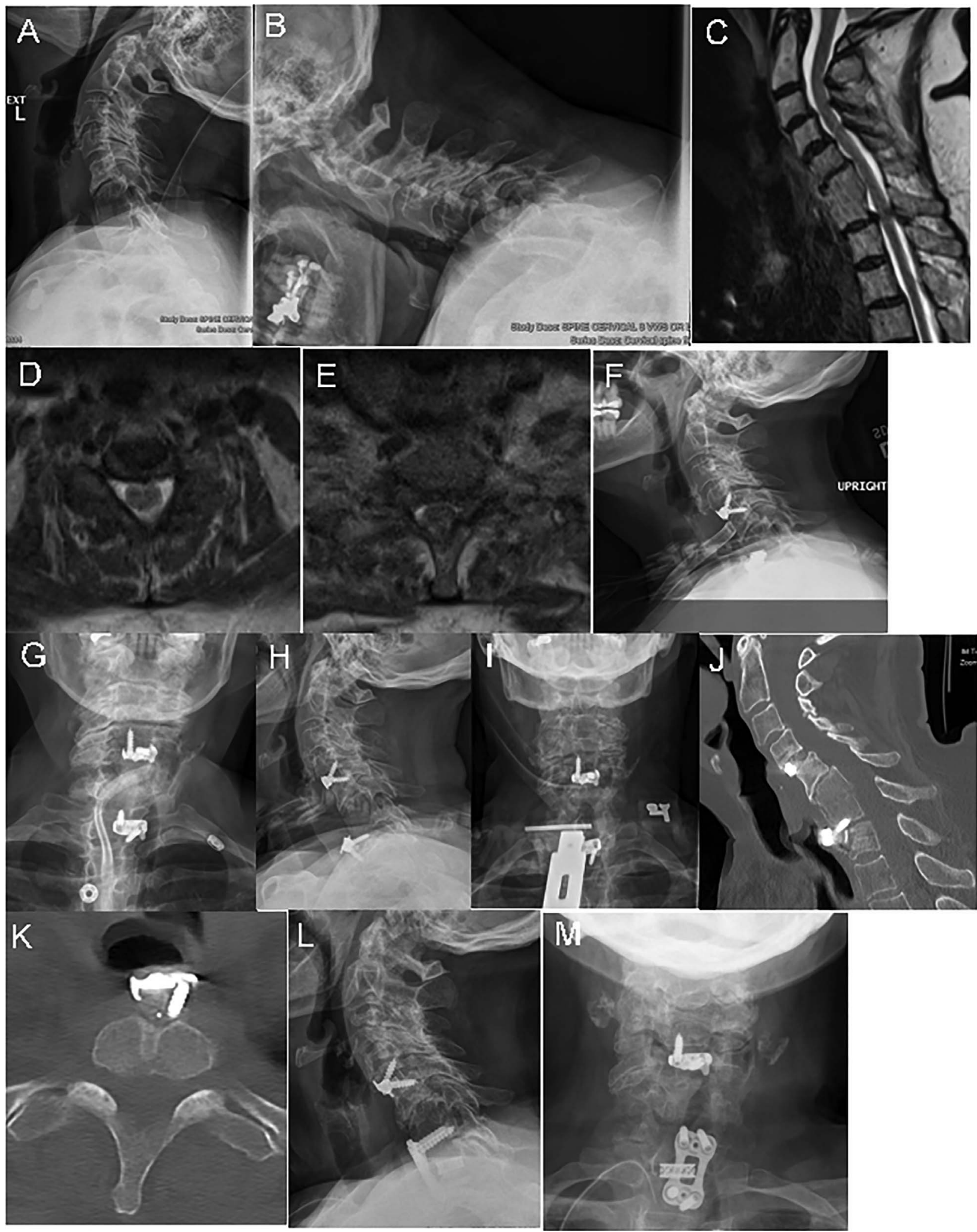

Figure. Case illustration. Preoperative lateral (A) extension and (B) flexion radiographs demonstrate dynamic spondylolisthesis at C4-5 and C7-T1. Preoperative magnetic resonance imaging with (C) sagittal and (D) axial cuts at C4-5 and (E) C7-T1 show disc herniations at those levels with moderate canal stenosis at C4-5 and severe canal stenosis at C7-T1. Postoperative (F) lateral and (G) anterior-posterior (AP) radiographs show placement of standalone constructs at C4-5 and C7T1. Interval $(\mathrm{H})$ lateral and (I) AP radiographs, as well as $(\mathrm{J})$ sagittal and $(\mathrm{K})$ axial computed tomography images 2 months later demonstrate hardware failure with anterior displacement of the $\mathrm{C} 7-\mathrm{T} 1$ standalone construct out of the disc space. Postrevision (L) lateral and (M) AP radiographs show implantation of a cage-and-plate construct at $\mathrm{C} 7-\mathrm{T} 1$. 
although the plated group displayed more improved cervical lordosis. ${ }^{3}$ Another meta-analysis pooled 11 studies and showed similar fusion rates but higher rates of subsidence with standalone cages. ${ }^{7}$

Our study found a revision rate of $8.7 \%$ in the standalone group compared with $3.6 \%$ in the plated group over the same period, although this did not reach statistical significance $(P=.125)$. Our multivariate analysis did not correlate the revision rate with number of levels fused, age, gender, tobacco use, diabetes status, BMI, or attending surgeon. In the standalone group, all 4 revisions were on Zero-P devices, with no revisions on Coalition MI or Scarlet devices. Caution is advised due to cases of biomechanical failure of the Zero-P device $^{28}$; however, these numbers are not adequately powered to make conclusive comparisons between devices. A lower degree of biomechanical stability with standalone cages may ultimately contribute to the higher rates of pseudarthrosis, subsidence, and/ or hardware failure. Scholz et al, testing 8 cadaver models with 2- and 3-level instrumentation with standalone PEEK cages, PEEK cages with locking plate, and zero-profile anchored spacers, showed a significantly decreased range of motion in lateral bending and flexion-extension with cage-and-plate constructs. ${ }^{4}$ In this way, greater stiffness and limitation of movement with the cage-and-plate constructs may provide a more conducive environment for bony fusion. Nevertheless, in our study, 4 of 10 revisions in the plated group were due to ASD, as opposed to 1 of 4 revisions in the standalone group, but this sample size is too small to make any definitive comparisons between construct types regarding ASD. Longer follow up with a larger sample size may be needed to reach significance in our study; however, our findings support the notion of decreased stability in standalone cages leading to a higher rate of pseudarthrosis or hardware failure. Furthermore, it is important to recognize the limitations of these constructs and be ready to convert to a different construct intraoperatively based on surgical anatomy.

\section{Dysphagia and Hoarseness}

Decreased incidences of dysphagia and hoarseness have been two of the most widely claimed benefits of the standalone cages. Some postulate that the thickness of the anterior cervical plate may lead to esophageal irritation and persistent dysphagia, with a lower-profile anchored standalone cage limiting irritation of the surrounding structures. ${ }^{16}$ Despite this theory, the literature reports varied rates of postoperative dysphagia and hoarseness, and the evidence remains equivocal. Several studies report no difference in postoperative dysphagia, ${ }^{21,23,29-31}$ while a few others report lower incidence with standalone constructs. ${ }^{22,26,32}$ Only 1 study commented on incidence of hoarseness, with a modestly greater improvement in voice handicap index in the standalone group. ${ }^{23}$ Comparing the standalone and cage-and-plate groups, our study showed similar rates of postoperative dysphagia (19.6\% in both groups) and hoarseness $(4.4 \%$ and $3.6 \%$, respectively), neither of which were statistically significant. In our multivariate analysis, incidence of dysphagia was significantly affected by the number of levels fused, which may affect the degree and duration of retraction on the esophagus. Advanced patient age, greater number of levels fused, and the attending surgeon's level of experience were all statistically significant factors predicting postoperative hoarseness in our cohort. Thus, our findings suggest that the implant may not play as significant of a role in postoperative dysphagia or hoarseness as compared with other patient demographic and surgical factors. Nevertheless, the 3 meta-analyses mentioned previously did find lower rates of dysphagia after implantation of standalone cages but only after pooling data across several studies, ${ }^{3,6,7}$ which implies that the modest reduction in dysphagia seen from standalone cages must be pooled over many patients to reach statistical significance.

\section{Procedure Duration and Blood Loss}

Additional reported benefits of standalone cages in the literature are decreased procedure duration and decreased operative blood loss. These factors have been directly attributed to the increased amount of dissection-exposure and time necessary to implant a plate and screws. When reviewing the literature, 2 studies reported shorter procedure duration with standalone cages, ${ }^{21,32}$ while 3 studies reported no difference between standalone and plated constructs. $^{22,23,25}$ Three meta-analyses investigated procedure duration - 1 reported no difference between constructs, ${ }^{8}$ and 2 reported shorter procedure duration with standalone cages, albeit with a high degree of heterogeneity among the studies in their analyses. ${ }^{3,7}$ In terms of blood loss, 2 studies reported lower EBL with standalone cag- 
es, ${ }^{25,32}$ while 1 study reported no difference between constructs. ${ }^{23}$ Three meta-analyses reported lower EBL with standalone cages but, again, with a high degree of heterogeneity among the studies in their analyses. ${ }^{3,7,8}$ Our experience challenges these findings. Procedure duration was marginally greater in the cage-and-plate group and did not reach statistical significance (147 minutes versus 151 minutes, $P$ $=.800)$. It was significantly affected, however, by number of levels fused and attending surgeon, specifically correlating to the level of experience of the surgeon. Mean EBL was higher in the standalone cage group than the cage-and-plate group (98 $\mathrm{mL}$ versus $63 \mathrm{~mL}, P=.001$ ), and it was significantly affected by the patient's smoking status, number of levels fused, and attending surgeon, again correlating with the level of experience of the surgeon. Looking at our results and the literature, we can conclude that standalone cages may offer marginal decreases in procedure duration and operative blood loss and that these metrics are also affected by a number of other surgical factors, namely the number of levels being operated on and the experience of the surgeon.

\section{Perioperative Metrics}

Our study also investigated several other perioperative metrics, including LOS, disposition, hospital readmission, and incidence of SSIs. LOS was not statistically significantly different between the standalone and cage-and-plated groups, and it was greater in diabetic patients, likely due to their propensity to have other medical comorbidities. When reviewing the literature, 3 studies explored LOS, and all 3 found no difference between standalone and cage-and-plated groups. ${ }^{23-25}$ One metaanalysis noted shorter LOS with standalone cages. ${ }^{3}$ There was no statistically significant difference between groups in terms of disposition to home versus rehabilitation, with diabetic patients and those diagnosed with myelopathy more likely to be discharged to rehabilitation facilities. No studies in the literature examined this metric. There was also no statistically significant difference between groups in terms of hospital readmission in our study. One smaller study found a lower readmission rate in the standalone group. ${ }^{22}$ Our study found a higher incidence of SSI in the standalone group $(2.2 \%$ versus $0 \%, P=.030$ ), and no other studies listed this metric. However, in general, rates of hospital readmission and SSI are quite low after ACDF.
These results, both our own and from the literature, suggest that there are not significant differences between standalone cages and plated constructs in terms of LOS, disposition, hospital readmission, and SSI and that diabetes is a potential complicating factor in these patients.

\section{Radiographic Outcomes}

Cervical spine radiographic parameters, including cervical lordosis, cervical SVA, and T1 slope, are important to track in these patients and are increasingly reported in the literature. Postoperative anterior-posterior and lateral radiographs were available for review in 180 of the 321 patients in our cohort, and we compared these parameters based on standalone versus plated constructs, as well as need for revision surgery. Interestingly, we found no significant difference in cervical lordosis, cervical SVA, or T1 slope between the standalone and cage-and-plate groups or between the revision and nonrevision groups. On dynamic films, we did find that more patients in the standalone group had a change in interspinous distance greater than $2 \mathrm{~mm}$ than in the cage-and-plate group $(87.5 \%$ versus $38.5 \%, P=.017$ ), which implies that the cage-andplate construct is more rigid and conducive for bony fusion. Nevertheless, this did not correlate with need for revision. When reviewing the literature, several studies showed greater segmental lordosis and segmental height with the cage-and-plate constructs. $^{24,27,33}$ Furthermore, 2 meta-analyses also found greater restoration of cervical lordosis with cage-and-plate constructs. ${ }^{3,6}$ Thus, cage-and-plate constructs can provide more stability and better alignment than standalone cages.

\section{Limitations}

There are several limitations to our study, the first of which is the retrospective nature of our analysis and its limitation to a single institution. Despite our large sample size, there were significantly more patients in the cage-and-plate group than in the standalone group, which can skew the multivariate analysis. Our sample size and reliance on retrospective documentation limit the conclusions that we can draw regarding specific outcomes measures. We excluded patients with prior cervical spine surgery, which excluded a significant number of standalone cases, since those constructs are commonly used for ASD cases. Additionally, 1 attending surgeon performed more of the standalone ACDFs, which 
can further skew the analysis and add selection bias, and surgeon experience with specific devices may influence outcomes. When tracking incidence of dysphagia and hoarseness, we did not have objective measures or scales and instead relied on clinical documentation. Other objective clinical measures, such as pain scores or neck disability index scores, would have added to our study. In terms of radiographic follow up, we did not have a standardized preoperative and postoperative imaging protocol to evaluate radiographic changes between the 2 groups analyzed. Only a small subset of patients underwent flexion-extension $\mathrm{x}$ rays and were included in our analysis of fusion-stability, which limits the power of our radiographic statistics. A more thorough tracking and analysis of ASD over a longer period is also necessary but was not the focus of this study.

\section{CONCLUSIONS}

Our literature review suggests that standalone ACDF constructs may offer modest decreases in operative time, blood loss, and dysphagia but provide less stable fixation and less restoration of cervical lordosis. Our study did not show these benefits but also did not show any difference in cervical spine radiographic parameters. We did show a higher, but not statistically significant, rate of revision surgery than conventional plate-andscrew constructs, as well as greater motion on dynamic radiographs. Spine surgeons may consider limiting use of these constructs to adjacent segment operations or on a case-by-case basis taking patient comorbidities into consideration. Larger studies with longer follow up are necessary to make more definitive conclusions.

\section{REFERENCES}

1. Angevine PD, Arons RR, McCormick PC. National and regional rates and variation of cervical discectomy with and without anterior fusion, 1990-1999. Spine (Phila Pa 1976). 2003;28(9):931-939. doi:10.1097/01.BRS.0000058880.89444.A9

2. Fraser JF. Anterior approaches to fusion of the cervical spine: a metaanalysis of fusion rates. $J$ Neurosurg. 2007;6(4):6. doi:10.3171/spi.2007.6.4.2

3. Zhang D, Liu B, Zhu J, et al. Comparison of clinical and radiologic outcomes between self-locking stand-alone cage and cage with anterior plate for multilevel anterior cervical discectomy and fusion: a meta-analysis. World Neurosurg. 2019;125:e117-e131. doi:10.1016/j.wneu.2018.12.218

4. Scholz M, Schleicher P, Pabst S, Kandziora F. A zeroprofile anchored spacer in multilevel cervical anterior interbody fusion: biomechanical comparison to established fixation techniques. Spine (Phila Pa 1976). 2015;40(7):E375-E380. doi:10.1097/BRS.0000000000000768

5. Vanek P, Bradac O, DeLacy P, Lacman J, Benes V. Anterior interbody fusion of the cervical spine with Zero-P spacer: prospective comparative study - clinical and radiological results at a minimum 2 years after surgery. Spine (Phila Pa 1976). 2013;38(13):E792-E797. doi:10.1097/BRS.0b013e3182913400

6. Cheung ZB, Gidumal S, White S, et al. Comparison of anterior cervical discectomy and fusion with a stand-alone interbody cage versus a conventional cage-plate technique: a systematic review and meta-analysis. Global Spine $J$. 2019;9(4):446-455. doi:10.1177/2192568218774576

7. Duan Y, Yang Y, Wang Y, et al. Comparison of anterior cervical discectomy and fusion with the zero-profile device versus plate and cage in treating cervical degenerative disc disease: a meta-analysis. J Clin Neurosci. 2016;33:11-18. doi:10. 1016/j.jocn.2016.01.046

8. Shao H, Chen J, Ru B, et al. Zero-profile implant versus conventional cage-plate implant in anterior cervical discectomy and fusion for the treatment of degenerative cervical spondylosis: a meta-analysis. J Orthop Surg Res. 2015;10:148. doi:10. 1186/s13018-015-0290-9

9. Ames CP, Blondel B, Scheer JK, et al. Cervical radiographical alignment: comprehensive assessment techniques and potential importance in cervical myelopathy. Spine (Phila Pa 1976). 2013;38(22 Suppl 1):S149-S160. doi:10.1097/ BRS.0b013e3182a $7 \mathrm{f} 449$

10. Kaiser MG, Mummaneni PV, Matz PG, et al. Radiographic assessment of cervical subaxial fusion. $J$ Neurosurg Spine. 2009;11(2):221-227. doi:10.3171/2009.3.SPINE08719

11. Oshina M, Oshima Y, Tanaka S, Riew KD. Radiological fusion criteria of postoperative anterior cervical discectomy and fusion: a systematic review. Global Spine J. 2018;8(7):739-750. doi: $10.1177 / 2192568218755141$

12. Ng EP-L, Yip AS-L, Wan KH-M, et al. Stand-alone cervical cages in 2-level anterior interbody fusion in cervical spondylotic myelopathy: results from a minimum 2-year followup. Asian Spine J. 2019;13(2):225-232. doi:10.31616/asj.2018. 0193

13. Njoku I, Alimi M, Leng LZ, et al. Anterior cervical discectomy and fusion with a zero-profile integrated plate and spacer device: a clinical and radiological study. J Neurosurg Spine. 2014;21(4):529-537. doi:10.3171/2014.6.SPINE12951

14. Han SY, Kim HW, Lee CY, Kim HR, Park DH. Standalone cages for anterior cervical fusion: are there no problems? Korean J Spine. 2016;13(1):13-19. doi:10.14245/kjs.2016.13.1.13

15. Kim SY, Yoon SH, Kim D, Oh CH, Oh S. A prospective study with cage-only or cage-with-plate fixation in anterior cervical discectomy and interbody fusion of one and two levels. J Korean Neurosurg Soc. 2017;60(6):691-700. doi:10.3340/jkns. 2017.0211

16. Lee Y-S, Kim Y-B, Park S-W. Does a zero-profile anchored cage offer additional stabilization as anterior cervical plate? Spine (Phila Pa 1976). 2015;40(10):E563-E570. doi:10. 1097/BRS.0000000000000864

17. Oh JK, Kim TY, Lee HS, et al. Stand-alone cervical cages versus anterior cervical plate in 2-level cervical anterior interbody fusion patients: clinical outcomes and radiologic changes. J Spinal Disord Tech. 2013;26(8):415-420. doi:10.1097/ BSD.0b013e31824c7d 22

18. Yun D-J, Lee S-J, Park S-J, et al. Use of a zero-profile device for contiguous 2-level anterior cervical diskectomy and 
fusion: comparison with cage with plate construct. World Neurosurg. 2017;97:189-198. doi:10.1016/j.wneu.2016.09.065

19. Baker JF, Gomez J, Shenoy K, Kim S, Razi A, Kim Y. A radiographic follow-up study of stand-alone-cage and graftplate constructs for single-level anterior cervical discectomy and fusion. J Spine Surgery. 2017;3(4):596-600. doi:10.21037/jss. 2017.11.06

20. Kwon OI, Son DW, Lee SW, Song GS. Comparison of radiologic outcomes of different methods in single-level anterior cervical discectomy and fusion. Korean J Spine. 2016;13(3):9196. doi:10.14245/kjs.2016.13.3.91

21. Nemoto O, Kitada A, Naitou S, Tachibana A, Ito Y, Fujikawa A. Stand-alone anchored cage versus cage with plating for single-level anterior cervical discectomy and fusion: a prospective, randomized, controlled study with a 2-year follow-up. Eur J Orthop Surg Traumatol. 2015;25(S1):127-134. doi:10.1007/s00590-014-1547-4

22. Overley SC, Merrill RK, Leven DM, Meaike JJ, Kumar A, Qureshi SA. A matched cohort analysis comparing standalone cages and anterior cervical plates used for anterior cervical discectomy and fusion. Global Spine J. 2017;7(5):394399. doi: $10.1177 / 2192568217699211$

23. Panchal RR, Kim KD, Eastlack R, et al. A clinical comparison of anterior cervical plates versus stand-alone intervertebral fusion devices for single-level anterior cervical discectomy and fusion procedures. World Neurosurg. 2017;99:630-637. doi:10.1016/j.wneu.2016.12.060

24. Perrini P, Cagnazzo F, Benedetto N, Morganti R, Gambacciani C. Cage with anterior plating is advantageous over the stand-alone cage for segmental lordosis in the treatment of two-level cervical degenerative spondylopathy: a retrospective study. Clin Neurol Neurosurg. 2017;163:27-32. doi:10.1016/j.clineuro.2017.10.014

25. Tabaraee E, Ahn J, Bohl DD, et al. Comparison of surgical outcomes, narcotics utilization, and costs after an anterior cervical discectomy and fusion: stand-alone cage versus anterior plating. Clin Spine Surg. 2017;30(9):E1201-E1205. doi:10.1097/BSD.0000000000000341

26. Yang L, Gu Y, Liang L, et al. Stand-alone anchored spacer versus anterior plate for multilevel anterior cervical diskectomy and fusion. Orthopedics. 2012;35(10):e1503-e1510. doi:10.3928/01477447-20120919-20

27. Zhu D, Zhang D, Liu B, Li C, Zhu J. Can self-locking cages offer the same clinical outcomes as anterior cage-withplate fixation for 3-level anterior cervical discectomy and fusion (ACDF) in mid-term follow-up? Med Sci Monit. 2019;25:547557. doi:10.12659/MSM.911234

28. Mattei TA, Teles AR, Dinh DH. Vertebral body fracture after anterior cervical discectomy and fusion with zero-profile anchored cages in adjacent levels: a cautionary tale. Eur Spine J. 2020;29(5):943-952. doi:10.1007/s00586-015-4358-3
29. Bazaz R, Lee MJ, Yoo JU. Incidence of dysphagia after anterior cervical spine surgery: a prospective study. Spine (Phila $P a$ 1976). 2002;27(22):2453-2458. doi:10.1097/00007632200211150-00007

30. Fisahn C, Schmidt C, Rustagi T, et al. Comparison of chronic dysphagia in standalone versus conventional plate and cage fusion. World Neurosurg. 2018;109:e382-e388. doi:10. 1016/j.wneu.2017.09.188

31. Haws BE, Khechen B, Patel DV, et al. Swallowing function following anterior cervical discectomy and fusion with and without anterior plating: a SWAL-QOL (swallowingquality of life) and radiographic assessment. Neurospine. 2019;16(3):601-607. doi:10.14245/ns.1836188.094

32. Zhou J, Li J, Lin H, Li X, Zhou X, Dong J. A comparison of a self-locking stand-alone cage and anterior cervical plate for ACDF: minimum 3-year assessment of radiographic and clinical outcomes. Clin Neurol Neurosurg. 2018;170:73-78. doi:10.1016/j.clineuro.2018.04.033

33. Kwon W-K, Kim PS, Ahn SY, et al. Analysis of associating factors with C2-7 sagittal vertical axis after twolevel anterior cervical fusion: comparison between plate augmentation and stand-alone cages. Spine (Phila Pa 1976). 2017;42(5):318-325. doi:10.1097/BRS.0000000000001776

Disclosures and COI: Dr Faheem Sandhu receives royalties from Globus and Spineart for standalone devices. The other authors report no conflict of interest concerning the materials or methods used in this study or the findings specified in this paper. This abstract was presented in poster format at the American Association of Neurological Surgeons national meeting on April 13-17, 2019, in San Diego, CA. Georgetown University IRB: STUDY00000609.

Corresponding Author: Islam Fayed, MD, MS, MedStar Georgetown University Hospital, Department of Neurosurgery, 3800 Reservoir Road NW, 7PHC, Washington, DC 20007. Phone: (862) 201-1260; Email: islam.f.fayed@gmail.com.

Published 1 June 2021

This manuscript is generously published free of charge by ISASS, the International Society for the Advancement of Spine Surgery. Copyright (C) 2021 ISASS. To see more or order reprints or permissions, see http://ijssurgery.com. 